\title{
Forced Expiratory Volume in 1 Second to Forced Vital Capacity Ratio Measurement
}

National Cancer Institute

\section{Source}

National Cancer Institute. Forced Expiratory Volume in 1 Second to Forced Vital Capacity

Ratio Measurement. NCI Thesaurus. Code C111359.

The proportion of total forced vital capacity that is expelled during the first second of a forced exhalation. 